\title{
MODELING RELATIONSHIPS BETWEEN INNOVATION ANTECEDENTS AND SERVICE INNOVATION: A ZIMBABWEAN HOTEL MANAGERS PERSPECTIVES
}

\author{
Abigail CHIVANDI \\ School of Economics and Business Sciences, Faculty of Commerce, Law and Management, University of the \\ Witwatersrand, Private Bag 3, WITS, 2050, Johannesburg, South Africa, e-mail: Abigail.Chivandi@wits.ac.za

\section{Eugine Tafadzwa MAZIRIRI*} \\ School of Economics and Business Sciences, Faculty of Commerce, Law and Management, University of the \\ Witwatersrand, Private Bag 3, WITS, 2050, Johannesburg, South Africa, e-mail: Eugine.Maziriri@wits.ac.za
}

\begin{abstract}
Citation: Chivandi, A., \& Maziriri, E.T. (2018). MODELING RELATIONSHIPS BETWEEN INNOVATION ANTECEDENTS AND SERVICE INNOVATION: A ZIMBABWEAN HOTEL MANAGERS PERSPECTIVES. GeoJournal of Tourism and Geosites, 23(3), 633-643. https://doi.org/10.30892/gtg.23301-315
\end{abstract}

\begin{abstract}
There seem to be a paucity of studies that have investigated the influence of learning philosophy, strategic direction, and transfunctional acclimation service innovation in the Zimbabwean context in the hospitality sector. This is a new trend that is becoming prevalent in service innovation orientation at the global level. The purpose of the study was to examine the relationship between innovation antecedents and service innovation in the hospitality sector of Zimbabwe as this provides leeway towards a major contribution of the GDP of most emerging countries and Zimbabwe is no exception. A quantitative approach was utilised and Smart PLS statistical software for structural equation modelling was used to analyse data. The results indicate that there is a positive and a significant relationship between innovation antecedents and service innovation. However, the relationship between trans-functional acclimation and service innovation was insignificant. The empirical study provided interesting implications to academicians by making a significant contribution to service innovation literature knowledge. This study incalculably adds to ground-breaking knowledge to the existing body of service innovation literature in emerging countries.
\end{abstract}

Key words: learning philosophy, strategic direction, transfunctional acclimation, service innovation, hotels

\section{INTRODUCTION}

Over the past decade, the service economy has been growing rapidly and may lead to an increase in employment, competitiveness, innovation and economic growth (Tether, 2005). According to Zulkepli, Hasnan and Mohtar (2015), services are provided in all

\footnotetext{
${ }^{*}$ Corresponding author
} 
types of business, ranging from SMEs, joint ventures, consulting firms, internet services, transport, tourism, social welfare, telecommunication services, and others. Innovation in services has received great attention in organisational studies due to its impact on society, especially with regard to the direct influence on the creation of jobs and social and economic development (Gallouj, 2007). Most services in tourism are based on human (employee) performance, services are produced and consumed simultaneously in a faceto-face exchange situation and employees and customers are physically and psychologically close enough to influence each other (Turanligil \& Altintaş, 2018).

The success of the hotel industry depends heavily on the social and technical skills of its personnel, their ingenuity and hard work, their commitment and attitude (Turanligil \& Altintaş, 2018). In this sense, the attainment of innovation enables better organisational performance, which is reflected in growth and productivity (Ferraz et al., 2016). It is imperative to note that, despite the theoretical contributions made by many scholars on innovation antecedents and service innovation, little is known pertaining to the connection between innovation antecedents (firm's learning philosophy, strategic direction, and transfunctional acclimation) and service innovation in the hospitality sector in Zimbabwe. Previous researchers in Zimbabwe have examined hotels and the hospitality sector in various contexts by focusing on an analysis of Zimbabwean hotel managers' perspectives on workforce diversity (Mkono, 2010); a study into guests' perceptions of service quality and loyalty in hotel restaurants in Harare (Mangwiro et al., 2015); the effects of dollarisation on human resources in the hospitality industry in Zimbabwe (Kabote, et al., 2014); challenges facing the use of energy in the tourism and hospitality industry in Zimbabwe and policies that can promote the sustainable use of renewable energy and tourism development (Marunda et al., 2013), as well as the effect of business soft skills on service delivery in the hospitality industry in Harare, Zimbabwe (Wushe et al., 2014).

In light of the above lacuna, the researchers are convinced that there is a dearth of studies that have investigated the relationship between innovation antecedents (firm's learning philosophy, strategic direction, and transfunctional acclimation) and service innovation in the context of developing countries in Africa. This justifies the need for the current empirical study. Furthermore, it is also essential to mention that there is limited literature that focuses on innovation antecedents, and the relationship between innovation antecedents (firm's learning philosophy, strategic direction, \& transfunctional acclimation) as the predictor variables of service innovation. Therefore, on the basis of the research gaps mentioned, this study examines the relationship between innovation antecedents (firm's learning philosophy, strategic direction, and transfunctional acclimation) and service innovation in the hospitality sector in Zimbabwe.

\section{Theoretical Rationale}

The literature that underpins the current study is based upon learning philosophy, strategic direction, trans-functional acclimation as well as service innovation; the following discussion focuses on the literature.

Learning philosophy: Requisite to an innovation-oriented firm is a learning philosophy which is defined as a pervasive set of organisation-wide understanding about learning, thinking, and acquiring, transferring, and using knowledge in the firm to innovate (Siguaw et al., 2006). Kearney (2015) argues that a learning philosophy is akin to a learning climate where the values and information processing in the organisational context dictate the causal mechanism through which people understand the nature of innovation. Moreover, a learning philosophy implies that innovation orientation is directed towards application of the learning processes at the functional management and staff level (Orfila-Sintes, 2009). 
Strategic direction: According to Siguaw, Simpson and Enz (2006), the strategic component of an innovation orientation "reflects the strategic directions implemented by a firm to create the proper behaviors for the continuous superior performance of the business". Strategic direction assumes the firm takes a future-oriented perspective, driven by management, and may be seen to be captured in the 'beliefs and understandings' that define the firm and how it approaches competitive challenges with regard to innovation (Kearneyk, 2015). Strategic direction involves clarity of thought and purpose and is generally articulated through vision and mission statements and objectives (Siguaw, Simpson \& Enz, 2006). In addition, effective strategic direction involves clear management of the firm's culture through the capability to change norms and values (Kearney, 2015). Moreover, Keene and Singh (2015) point out that strategic direction is the stated long-term beliefs, understandings and activities of the organisation.

Trans-functional acclimation: Trans-functional acclimation refers to the beliefs about working across functional units, commonly referred to as silos (Keene \& Singh, 2015). Trans-functional acclimation is giving and delivering knowledge across the business sub-divisions so as to return diversity of points and also affecting beliefs and understanding that direct thems towards innovation (Zhou et al., 2005). Moreover, as a variable, trans-functional acclimation assists the functional line management and employees of the hotel to gain knowledge in service delivery and its strategies that will enhance service innovation (Siguaw et al., 2006).

Service innovation: According to Ryu and Lee (2012), service innovation can be related to changes in various characteristics of the service product itself. In addition, Vos (2010) is of the view that a service innovation is a new service or such a renewal of an existing service which is put into practice and which provides benefit to the organisation that has developed it; the benefit usually derives from the added value that the renewal provides to the customers. Furthermore, Kjos (2013) points out that service innovation is a multi-stage process whereby organisations transform ideas into new or improved services, in order to advance, compete and differentiate themselves successfully in their marketplace. Moreover, Randhawa and Scerri (2015) conceptualise service innovation as an "elevated service offering" that is made up of "new client interface/customer encounter; new service delivery system; new organizational architecture or marketing proposition; and/or improvements in productivity and performance through human resource management", further highlighting its multidimensional aspects.

\section{Conceptual model and hypothesis development}

The foregoing discussion of the literature culminated in the formulation of the conceptual framework illustrated in Figure 1.

\section{Learning philosophy and strategic direction}

It is vital to elucidate the nexus between learning philosophy and strategic direction. According to Wood and Brotherton (2008), a culture that supports innovation encourages employees and managers to challenge old ideas by instilling a commitment to continuous learning and strategic change. The work of Marsick and Watkins (2003) also concur that creating a culture that is conducive to learning is imperative to achieve a rewarding working place that encourages the development of employees' capacity to learn. Beyene, et al., (2016) are of the view that the learning effort of an organisation should be directed by a predefined strategic objective that can lead to shared interpretation of the information. Based on the foregoing discourse, it is logical for one to presuppose that a positive linkage exist between learning philosophy and strategic direction in the context under consideration in this study. As such, the following hypothesis is proposed: 


\section{$H_{1}$ : Learning philosophy has a positive relationship with strategic direction}

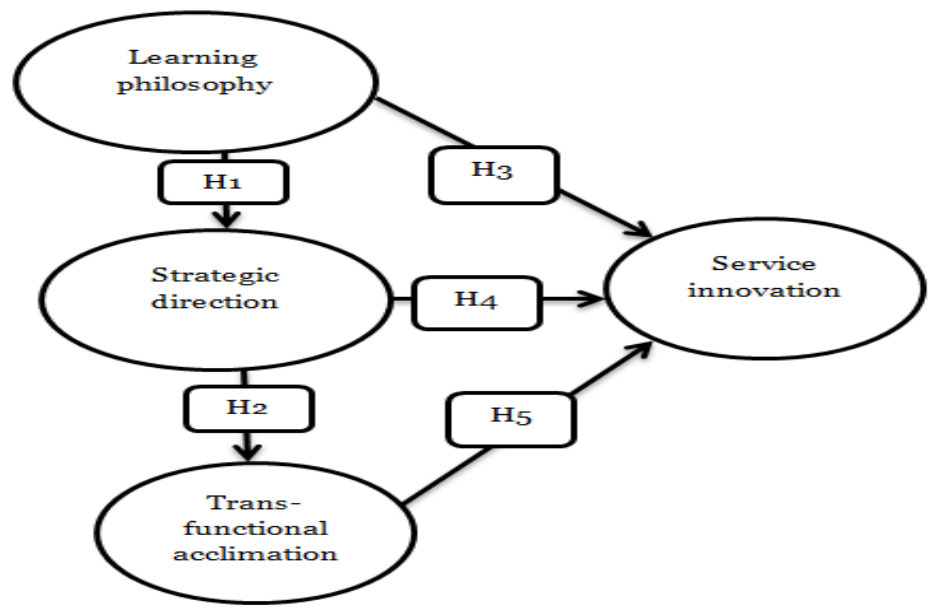

Figure 1. Conceptual model

\section{Strategic direction and trans-functional acclimation}

The strategic component of an innovation oriented firm reflects the strategic directions implemented by a firm to create the proper behaviours for a continuous superior performance of the business (Gatignon \& Xuereb, 1997). In essence, this component is the way of thinking and leading that drives the firm over the long run, keeping it innovative (Barba-Sánchez et al., 2007). On the other hand, trans-functional acclimation is generally seen as a set of common understandings and beliefs, pervading the innovation orientated firm that creates a unifying comradeship, enthusi-asm, and devotion among employees (Worren et al., 2002). According to Ndhlovu (2016), a strategic measure for improving the operations of small to medium size hotels is transfunctional acclimation. In a nutshell, from the authors' elucidations, it can be noted that when there is strategic direction within an organisation, such as an hotel, it promotes mutual understanding as well as beliefs among hotel employees and this is a true reflection of trans-functional acclimation. This study proposes that:

\section{acclimation}

$\mathrm{H}_{2}$ : Strategic direction has a positive relationship with trans-functional

\section{Learning philosophy and service innovation}

To establish the learning philosophy in the hotel sector, the definition of "learning philosophy" as given by Siguaw, Simpson and Enz (2006) is adopted. The critical question that then arises is whether the learning philosophy variable influences service innovation in the hotel sector. The promotion of the development and adoption of an innovative environment is recognised as a major push factor for creativity (Amabile, 1996). In the context of the hospitality/hotel services sector, an environment that promotes innovation creates an ideal learning environment and helps in building the relationships between the employee, organisation and the delivery of service performance in order to satisfy the customer. This is supported by the theory of reasoned action (TORA) which states that it is likely that the hotel will have improved services which lead to repeat purchases and in the long run, the relationships are built between the customer and the hotel as an entity. The learning philosophy, in 
conjunction with service innovation, helps in creating and redesigning services and the learning environment that satisfy the customers in the consumption of services and promotes relationship marketing. Based on the foregoing discussion, it appears that there is a positive association between learning philosophy and service innovation. This being the case, the following hypothesis is put forward:

\section{innovation}

$\mathrm{H}_{3}$ : Learning philosophy has a positive relationship with service

\section{Strategic direction and service innovation}

It is of significance to assess the relationship that exists between strategic direction and service innovation. In order for the hotel to achieve service innovation, there is a need for their innovation orientation to be in alignment with the planning, designing, recreating and responding to all these factors during their service processes (Zhou et al., 2005). If the above mentioned factors in strategic direction can be considered in the hotel, a measurement in attaining the service innovation and the output performance will be improved (Agwaral \& Selen, 2009). Innovation occurs when appropriate strategies are implemented. When management and employees are receptive to innovation, it is easier to create and implement new ideas and business designs that result in service innovation. In a hotel set up, such an approach gives the service offering competitive advantage as it relates to a good hotel image. Hence, following this line of discussion, it is hypothesised that:

\section{innovation}

$H_{4}$ : Strategic direction has a positive relationship with service

\section{Trans-functional acclimation and service innovation}

Moreover, it is also imperative to elucidate on the relationship that exists between trans-functional acclimation and service innovation. Trans-functional acclimation facilitates and encourages the sharing of knowledge across departments in order to tap into a multiplicity of views and beliefs among all the functional areas in order to direct them towards innovation (Zhou et al., 2005). This variable, transfunctional acclimation assists the functional line management and employees of the hotel to gain knowledge in service delivery and its strategies that will enhance service innovation (Siguaw et al., 2006). The hotels with large service offering capacity are more likely to innovate and develop new capabilities to facilitate improved business performances (Berthon et al., 1996). Therefore, this paper postulates that there is a positive link between trans-functional acclimation and service innovation. Following from this, it may be hypothesised that:

\section{$\mathrm{H}_{5}$ : Trans-functional acclimation has a positive relationship with service innovation}

\section{METHODOLOGY}

The data for this research was obtained from city centre and resort-based hotels in Zimbabwe. The research sampling frame was the Rainbow tourism group of hotels, the African Sun group of hotels, as well as affiliate lodges ranging from $3^{* * *}$ to $5^{* * * *}$ graded hotels. The list of hotels was obtained from the Zimbabwe Tourism Authority (ZTA) in Zimbabwe. Due to the nature of this research, the targeted research participants were the hotel managers. In particular, officials who occupied top managerial positions, hotel employees and Ministry of Tourism and hospitality industry employees were approached. This was done to ensure the competence of the respondents in evaluating the hotels' service innovation, financial performance, customer retention and hotel reputation. A self-administered structured questionnaire was used as the research instrument and out 
the total of 170 questionnaires distributed, 151 usable questionnaires were retrieved for the final data analysis, representing a response rate of $88.9 \%$.

\section{Sample description}

Descriptive statistics in Table: 1 show the gender, position and department of respondents who participated in the study. As indicated in Table 1, this study shows that fewer females participated in the study and constitute $36 \%(n=55)$ of the total target population. Male consumers who participated in the study were $64 \%(n=96)$ of the total population. In terms of the positions, most of the respondents $(30 \% ; n=45)$ indicated that there are front line staff member and the least of the respondents (17\%; $\mathrm{n}=26$ ) indicated that they are General Managers. Moreover, in terms of the departments in which the respondents are working, the majority which are $40 \%(n=60)$ of the respondents indicated that they work within the food and beverage department, the least respondents were $2 \%(n=3)$ from the personnel department respectively.

Table 1. Sample demographic characteristics

\begin{tabular}{|l|c|c|}
\hline \multicolumn{1}{|c|}{ Gender } & Frequency & Percentage \\
\hline Male & 96 & $64 \%$ \\
\hline Female & 55 & $36 \%$ \\
\hline Total & $\mathbf{1 5 1}$ & $\mathbf{1 0 0 \%}$ \\
\hline \multicolumn{1}{|c|}{ Position } & Frequency & Percentage \\
\hline Front Line Staff & 41 & $\mathbf{2 7 \%}$ \\
\hline Supervisor & 45 & $30 \%$ \\
\hline Unit Director & 39 & $\mathbf{2 6 \%}$ \\
\hline General Manager & $\mathbf{2 6}$ & $17 \%$ \\
\hline Total & $\mathbf{1 5 1}$ & $\mathbf{1 0 0 \%}$ \\
\hline Department & Frequency & Percentage \\
\hline Food and Beverage & 60 & $40 \%$ \\
\hline Housekeeping & $\mathbf{2 0}$ & $13 \%$ \\
\hline Personnel & 3 & $\mathbf{2} \%$ \\
\hline IT & 9 & $6 \%$ \\
\hline Restaurant Services & 43 & $30 \%$ \\
\hline Marketing & 5 & $3 \%$ \\
\hline Support Services & $\mathbf{1 1}$ & $7 \%$ \\
\hline Total & $\mathbf{1 5 1}$ & $\mathbf{1 0 0 \%}$ \\
\hline
\end{tabular}

\section{Scale accuracy analysis}

Reliability and validity of the measurement instruments proved to be good so the study proceeded to test the proposed hypotheses. In total, there were five hypotheses tested. The same results of the path coefficients are tabulated in Table 2 depicting the Item to Total correlations, Average variance extracted (AVE), Composite Reliability (CR) and Factor Loadings. As clarified above, T3 was deleted due to the fact that the factor loadings were below 0.5 which is the recommended threshold, according to Anderson and Gerbin (1988). Table 2 presents the research constructs, Cronbach alpha test, Composite reliability (CR), Average variance extracted (AVE) and item loadings. The lowest item to total loading is TA1 with 0.514 and the highest is LP4 with 0.787 . On Factor loadings, the lowest is SI1 with 0.538 and the highest is 0.898 which is TA1. This shows that the measurement instruments are valid. The lowest Cronbach alpha is 0.717 and the highest is 0.918 which shows that the constructs are very reliable and explain more that $50 \%$ of the variance. 


\section{Inter-Construct Correlation Matrix}

Nunnally and Bernstein (1994) prove that one of the methods used to check on the discriminant validity of the research constructs was the evaluation of whether the correlations among latent constructs were less than 0.60 . A correlation value of less than 0.60 is recommended in the empirical literature to confirm the existence of discriminant validity (Nunnally \& Bernstein, 1994). As can be seen, all the correlations are below the standard level of 0.60 which indicates the existence of discriminant validity.

Table 2. Measurement Accuracy Assessment and Descriptive Statistics

\begin{tabular}{|c|c|c|c|c|c|c|c|c|}
\hline \multicolumn{2}{|c|}{ Research constructs } & \multicolumn{2}{|c|}{$\begin{array}{l}\text { Descriptive } \\
\text { statistics }\end{array}$} & \multicolumn{2}{|c|}{ Cronbach's test } & \multirow{2}{*}{ C.R. } & \multirow[t]{2}{*}{ AVE } & \multirow{2}{*}{$\begin{array}{l}\text { Measurement } \\
\text { Item } \\
\text { Loadings }\end{array}$} \\
\hline & & Mean & SD & Item-total & a Value & & & \\
\hline \multirow{6}{*}{$\begin{array}{l}\text { Learning } \\
\text { Philosophy (LP) }\end{array}$} & LP1 & \multirow{6}{*}{0.412} & \multirow{6}{*}{1.117} & 0.630 & \multirow{6}{*}{0.763} & \multirow{6}{*}{0.834} & \multirow{6}{*}{0.458} & 0.572 \\
\hline & LP2 & & & 0.666 & & & & 0.687 \\
\hline & LP3 & & & 0.715 & & & & 0.586 \\
\hline & $\mathbf{L P}_{4}$ & & & 0.787 & & & & 0.713 \\
\hline & LP5 & & & 0.652 & & & & 0.749 \\
\hline & LP6 & & & 0.707 & & & & 0.735 \\
\hline \multirow{5}{*}{$\begin{array}{l}\text { Strategic } \\
\text { Direction (SD) }\end{array}$} & SD1 & \multirow{5}{*}{0.404} & \multirow{5}{*}{1.179} & 0.619 & \multirow{5}{*}{0.918} & \multirow{5}{*}{0.930} & \multirow{5}{*}{0.529} & 0.556 \\
\hline & SD2 & & & 0.761 & & & & 0.627 \\
\hline & SD3 & & & 0.715 & & & & 0.807 \\
\hline & SD4 & & & 0.569 & & & & 0.814 \\
\hline & SD5 & & & 0.531 & & & & 0.804 \\
\hline \multirow{2}{*}{$\begin{array}{l}\text { Transfunctional } \\
\text { Acclimation (TA) }\end{array}$} & TA1 & \multirow{2}{*}{0.419} & \multirow{2}{*}{1.490} & 0.514 & \multirow{2}{*}{0.778} & \multirow{2}{*}{0.848} & \multirow{2}{*}{0.532} & 0.898 \\
\hline & TA2 & & & 0.554 & & & & 0.602 \\
\hline \multirow{12}{*}{$\begin{array}{l}\text { Service } \\
\text { Innovation (SI) }\end{array}$} & SI1 & \multirow{12}{*}{0.396} & \multirow{12}{*}{1.137} & 0.561 & \multirow{12}{*}{0.717} & \multirow{12}{*}{0.730} & \multirow{12}{*}{0.584} & 0.538 \\
\hline & SI2 & & & 0.588 & & & & 0.690 \\
\hline & SI3 & & & 0.588 & & & & 0.699 \\
\hline & SI4 & & & 0.632 & & & & 0.734 \\
\hline & SI5 & & & 0.641 & & & & 0.749 \\
\hline & SI6 & & & 0.639 & & & & 0.724 \\
\hline & SI7 & & & 0.622 & & & & 0.695 \\
\hline & SI8 & & & $\begin{array}{l}0.552 \\
\end{array}$ & & & & 0.785 \\
\hline & SI9 & & & \begin{tabular}{|l}
0.559 \\
\end{tabular} & & & & 0.820 \\
\hline & SI10 & & & 0.602 & & & & 0.723 \\
\hline & SI11 & & & 0.600 & & & & 0.777 \\
\hline & SI12 & & & 0.634 & & & & 0.757 \\
\hline
\end{tabular}

Table 3. Inter-Construct Correlation Matrix

\begin{tabular}{|c|c|c|c|c|}
\hline Variables & LP & SD & TA & SI \\
\hline LP & $\mathbf{1 . 0 0 0}$ & & & \\
\hline SD & 0.427 & $\mathbf{1 . 0 0 0}$ & & \\
\hline TA & 0.420 & 0.430 & $\mathbf{1 . 0 0 0}$ & \\
\hline SI & 0.376 & 0.588 & 0.564 & $\mathbf{1 . 0 0 0}$ \\
\hline
\end{tabular}

Learning Philosophy = (LP);

Strategic Direction = (SD);

Trans-functional Acclimation = (TA);

Service Innovation $=(\mathrm{SI})$

\section{Global goodness-of-fit}

Smart PLS is a general technique for estimating paths involving latent constructs indirectly observed by multiple indicators (Bontis, 1998). However, Smart PLS software 
does not provide goodness-of-fit measures for the full path model as LISREL and AMOS do, but it provides only $\mathrm{R}^{2}$ values for the dependent variables. Conversely, a method to calculate a global goodness-of-fit (GoF) measure was proposed by Amato, Vinzi and Tenenhaus (2004), and this method takes into account both the quality of the measurement model and the structural model (Chinomona 2013; Streukens, 2008). The global goodness-of-fit (GoF) statistic was calculated using the following equation, as suggested by Tenenhaus, Vinzi, Chatelin and Lauro (2005):

$$
\mathrm{GoF}=\sqrt{ } \mathrm{AVE} * \mathrm{R}^{2}
$$

where AVE represents the average of all AVE values for the research variables while $\mathrm{R}^{2}$ represents the average of all $\mathrm{R}^{2}$ values in the full path model. The calculated global goodness of fit (GoF) is 0.61 , which exceeds the recommended threshold of GoF $>0.36$ suggested by Wetzels, Odekerken-Schröder and Van Oppen (2009) as well as Chinomona (2013). Thus, the study confirms the existence of the data's goodness-of-fit to the research model.

Path Model Results and Factor Loadings

Figure 2 shows the path modelling results, as well as the item loadings for the research constructs.

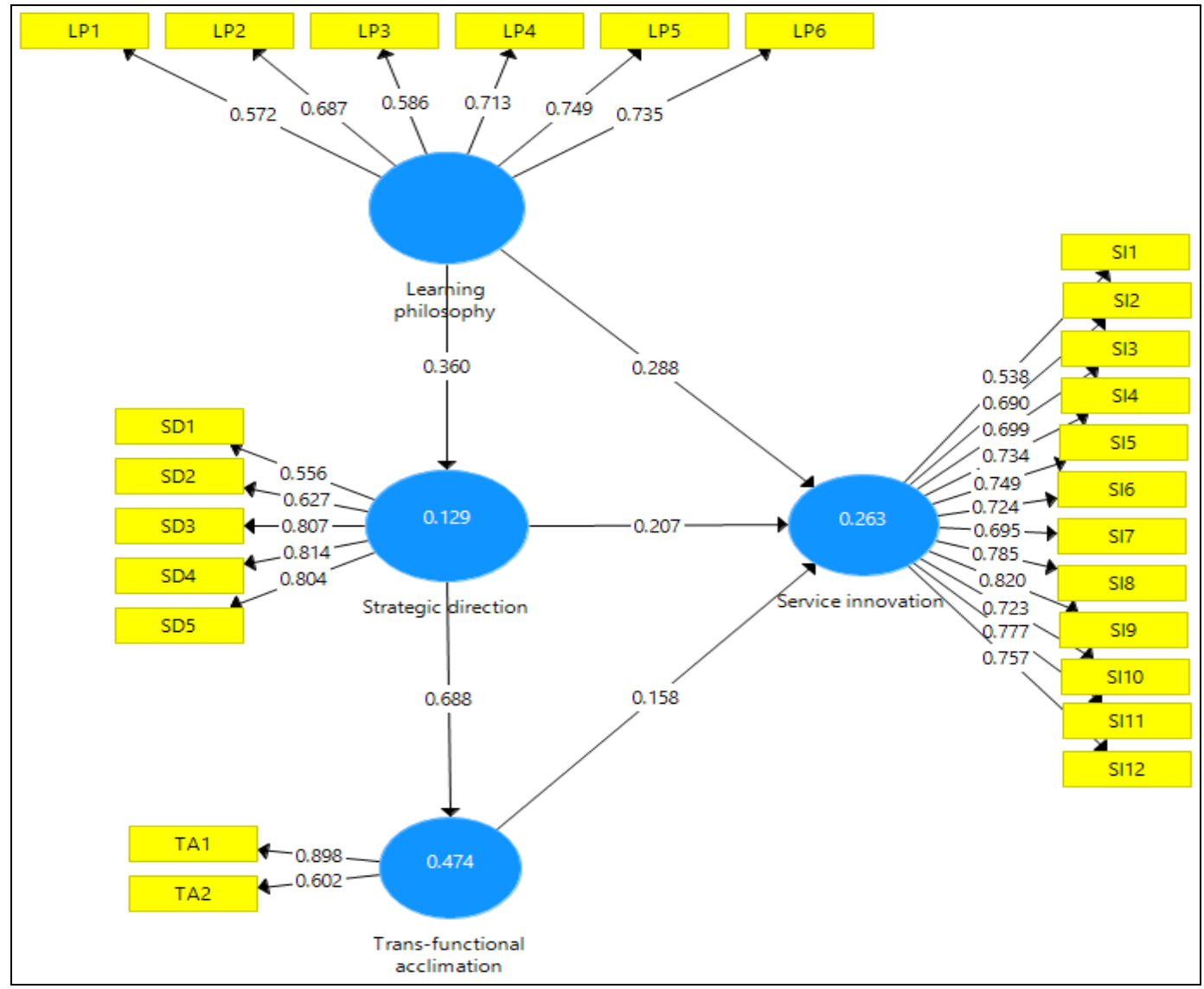

Figure 2. Path Modeling and Factor Loading Results 


\section{Research Findings and Discussions}

Hypothesis one $\left(\mathrm{H}_{1}\right)$ : Learning Philosophy $(\mathrm{LP}) \rightarrow$ Strategic Direction (SD)

Figure 2 and Table 4 also indicate that $\mathrm{H}_{1}$, Learning Philosophy (LP) to Strategic Direction (SD) is supported by the hypothesis finding (0.360) and is significant at tstatistics 4.645. Again, the strength of the association is indicated by a path coefficient of 0.360. This implies that learning philosophy (LP) is positively related to strategic direction (SD) in a significant way. Thus, higher levels of learning of staff in a hotel will lead to higher levels of strategic direction.

\section{acclimation}

Hypothesis two $\left(\mathrm{H}_{2}\right)$ : Strategic Direction (SD) $\rightarrow$ Trans-functional

It can be observed in Figure 2 and Table 4 that $\mathrm{H}_{2}$ Strategic Direction (SD) to Trans-functional Acclimation is supported by the hypothesis result (path coefficient) of 0.668 and is significant at t-statistics 3.543. The strength of the relationship is indicated by a path coefficient of 15.299 . This implies that strategic direction has a strong and significant impact on trans-functional acclimation.

Therefore, when a hotel has a well-grounded strategic direction, the higher the level of transfunctional acclimation will be.

Table 4. Results: structural equation model analysis

\begin{tabular}{|l|c|c|c|c|}
\hline \multicolumn{1}{|c|}{ Path } & Hypothesis & $\begin{array}{c}\text { Path coefficients } \\
(\boldsymbol{\beta})\end{array}$ & T-Statistics & $\begin{array}{c}\text { Decision on } \\
\text { Hypotheses }\end{array}$ \\
\hline $\begin{array}{l}\text { Learning Philosophy (LP) } \rightarrow \\
\text { Strategic Direction (SD) }\end{array}$ & $\mathrm{H} 1$ & $0.360^{\mathrm{a}}$ & 4.645 & Supported \\
\hline $\begin{array}{l}\text { Strategic Direction (SD) } \rightarrow \\
\text { Transfunctional acclimation (TA) }\end{array}$ & $\mathrm{H} 2$ & $0.688^{\mathrm{a}}$ & 15.299 & Supported \\
\hline $\begin{array}{l}\text { Learning Philosophy (LP) } \rightarrow \text { Service } \\
\text { innovation (SI) }\end{array}$ & $\mathrm{H} 3$ & $0.288^{\mathrm{a}}$ & 3.503 & Supported \\
\hline $\begin{array}{l}\text { Strategic Direction (SD) } \rightarrow \text { Service } \\
\text { innovation (SI) }\end{array}$ & $\mathrm{H} 4$ & $0.207^{\mathrm{a}}$ & 2.586 & Supported \\
\hline $\begin{array}{l}\text { Trans-functional acclimation } \\
\text { (TA) } \rightarrow \text { Service innovation (SI) }\end{array}$ & $\mathrm{H} 5$ & $0.150^{\mathrm{a}}$ & 1.637 & Not Supported \\
\hline
\end{tabular}

Hypothesis three $\left(\mathrm{H}_{3}\right)$ : Learning Philosophy (LP) $\rightarrow$ Service innovation (SI)

It can be observed in Figure 2 and Table 4 that $\mathrm{H}_{3}$ Learning philosophy (LP) to Service innovation (SI) is supported by the hypothesis result (path coefficient) of 0.288 and is significant at t-statistics 3.543. The strength of the relationship is indicated by a path coefficient of 0.288 . This implies that learning philosophy directly influences service innovation in a positive significant way. The more a hotel is engaged in learning, the higher the level of service.

\section{Hypothesis four $\left(\mathrm{H}_{4}\right)$ : Strategic Direction (SD) $\rightarrow$ Service innovation (SI)}

It is depicted in Figure 2 and Table 4 that $\mathrm{H}_{4}$, Strategic Direction (SD) to Service innovation (SI) is supported significantly. The t-statistics is 2.586. The strength of the relationship is indicated by the path coefficient of 0.207 . This finding suggests that strategic direction has a direct relationship with innovation, so when a hotel has a strategic direction, the more it is capable of engaging in service innovation.

Hypothesis five $\left(\mathrm{H}_{5}\right)$ : Trans-functional acclimation (TA) $\rightarrow$ Service innovation (SI)

Figure 2 and Table 4 also indicate that $\mathrm{H}_{5}$, Trans-functional acclimation (TA) to Service innovation (SI) is not supported, as indicated by the hypothesis finding (0.150) 
and is insignificant at t-statistics 1.637. This implies that trans-functional acclimation is not positively related to service innovation. An investigation of the research findings indicated that strategic direction and trans-functional acclimation has the strongest influence on each other, as indicated by a path coefficient of (o.688) when compared to other research constructs, therefore, for academicians in the field of innovation, this finding enhances their understanding of the relationship as this is a useful contribution to existing literature on these two variables. On the practitioners' side, this study also submits that hotel managers can benefit from the implications of these findings. For instance, given the robust relationship between learning philosophy and service innovation (0.288), hotel managers in Zimbabwe ought to establish a learning philosophy in order to be well engaged in service innovation. Precisely, employees can learn or they can be taught on how to renew an existing service which is a resemblance of service innovation.

\section{CONCLUSION}

The study substantiates that innovations have a positive relationship with service innovation except that of trans-functional acclimation. Learning Philosophy was found to have a high positive influence towards service innovation. Practically, this study makes an important contribution to the service industry, specifically the tourism and hospitality sector. Theoretically, this study contributes to the existing body of knowledge in the service innovation literature in hotels. The findings would have been more enlightening if data from all hotels in Zimbabwe were gathered as well as compared. Subsequent research should contemplate replicating this study in other developing countries for result comparisons. Furthermore, more valuable and insightful findings could have been found by conducting a longitudinal study of the influence of service innovation and its outcome in all hospitality/hotel sectors.

\section{Aknowlegments}

The authors acknowledge to anonymous reviewer/s for their thoughtful suggestions and comments.

\section{REFERENCES}

Amabile, T. (1996). Creativity in context. Westview press. New York.

Amato. S., Esposito, V.V. \& Tenenhaus, M. (2004). A global goodness-of-fit index for PLS structural equation modeling, France: Oral Communication to PLS Club, HEC School of Management.

Barba-Sánchez, V., Martínez-Ruiz, M. D. P., \& Jiménez-Zarco, A. I. (2007). Drivers, benefits and challenges of ICT adoption by small and medium sized enterprises (SMEs): a literature review. Problems and Perspectives in Management, no. 5 vol 1, p. 104-115.

Berthon, P.R., Hulbert, J.M. \& Pitt, L.F. (1996). Structuring companies for markets. Financial Times, 16 August:pp. 8-9.

Beyene, K. T., Shi, C. S., \& Wu, W. W. (2016). The impact of innovation strategy on organizational learning and innovation performance: Do firm size and ownership type make a difference? South African Journal of Industrial Engineering, no. 27 vol 1, p. 125-136.

Ferraz, I. N., \& de Melo Santos, N. (2016). The relationship between service innovation and performance: A bibliometric analysis and research agenda proposal. RAI Revista de Administração e Inovação, no. 13 vol 4 , p. 251-26o.

Gallouj, F. (2007). Economia da inovac, ão: Um balanc, o dos debates recentes. In R. Bernardes, \& T. Andreassi (Eds.), Inova, cão em servi, cos intensivos em conhecimento (pp. 3-27). São Paulo: Saraiva.

Gatignon, H. and Xuereb, J.M. (1997). "Strategic orientation of the firm and new product performance". Journal of Marketing Research, no 34 vol 1, p. 77-90.

Kabote, F., Vengesayi, S., Mamimine, P. W., \& Mataruse, R. (2014). The Effects of Dollarization on Human Resources in the Hospitality Industry in Zimbabwe. Journal of Business and Management, no. 16 vol 6, p. 65-71. 
Kearney, A (2015). Managerial capability for innovation in tourism micro firms, Doctor of Philosophy Thesis, Waterford Institute of Technology.

Keene, C \& Singh, M. (2015). Embedding Innovation How Large Organizations Can Succeed at Innovation in the Long Term, Master of Design (MDes) in Strategic Foresight and Innovation dissertation, OCAD University. Toronto, Ontario, Canada.

Kjos, K. (2013). The drivers of service innovation: a study of the drivers of service innovation in a start-up firm versus an established firm in the Norwegian healthcare sector. Master's thesis, Universitetet i Agder; University of Agder.

Mangwiro, M., Marimo, R.M., \& Ndlovu, A.O. (2015). A study into guest perceptions of service quality and loyalty in hotels in Harare. Research-journali's Journal of Hospitality Tourism. no. 2 vol 4, p. 1-12.

Marsick, V. J., \& Watkins, K. E. (2003). Demonstrating the value of an organization's learning culture: the dimensions of the learning organization questionnaire. Advances in developing human resources, no. 5 vol 2, p. 132-151.

Marunda, E., Sai, J.P., \& Muchenje, B. (2013). Challenges facing use of energy in the tourism and hospitality industry in Zimbabwe and policies that can promote the sustainable use of renewable energy and tourism development. International Journal of Development and Sustainability, no. 2 vol 2, p. $472-484$.

Mkono, M. (2010). An analysis of Zimbabwean hotel managers' perspectives on workforce diversity. Tourism and Hospitality Research, no. 10 vol 4, p. 301-310.

Ndhlovu, N. (2016). Embracing Innovative Business Strategies in Small to Medium Size Hotels in Harare, Zimbabwe: Challenges and Solutions, The international journal of business \& management, no. 4 vol 7, p. 263-270.

Nunnally, J.C \& Bernstein, I.H., (1994). Psychometric theory. New York: McGraw-Hill.

Orfila-Sintes, F. and Mattsson, J. (2009). Innovation behaviour in the hotel industry. The International Journal of Management Science, no. $37 \mathrm{vol}$ 2, p. 380-394.

Rainbow Tourism Group. (2013). The Rainbow Tourism Group Ltd. Retrieved from http://www.rtgafrica.com/ on 20 February 2015.

Randhawa, K. \& Scerri, M. (2015). Service innovation: A review of the literature. In The handbook of service innovation, Springer London. pp. 27-51.

Ryu, H. S. \& Lee, J.N. (2012). Identifying Service Innovation Patterns from the Service- Oriented Perspective. In PACIS, 60.

Siguaw, J.A., Simpson P.M. \& Enz, C.A. (2006). Conceptualizing innovation orientation: a framework for study and integration of innovation research. Journal of product innovation management, no. 23 vol 6, p. 556-574.

Streukens, S. (2008). On the use of partial least squares path modeling in organizational research: an overview and illustration of its possibilities. Working Paper, Hasselt University, Hasselt.

Tether, B. S. (2005). Innovation in services. Industry and Innovation, no. 12, vol 2, p. 153-184.

Tenenhaus, M., Vinzi, V. E., Chatelin, Y. M., \& Lauro, C. (2005). PLS path modeling. Computational statistics \& data analysis, no. 48, vol 1, p. 159-205.

Turanligil, F.G \& Altintaş, V. (2018). Analysis of Industry Perceptions and Expectations of Tourism Students: A Case Study in Turkey, GeoJournal of Tourism and Geosites, 21(1), 266-281

Vos, A. H. (2010). Service innovation: managing innovation from idea generation to innovative offer (Master's thesis, University of Twente).

Wood, R.C., \& Brotherton, B. (Eds.). (2008). The SAGE handbook of hospitality management. Thousand Oaks, CA. Sage.

Worren, N., Morre, K. and Carmona, P. (2002). "Modularity, strategy flexibility, and firm performance: A study of the home appliance industry”. Strategic Management Journal, 23 (12), pp. 1123-1140.

Wushe, T., Shenje, J., \& Ndlovu, D. (2014). Effect of business soft skills on service delivery in the hospitality industry in Harare, Zimbabwe. Journal of leadership and management studies, 1(2), pp. 185-203.

Zhou, K.Z., Gao, G.Y., Yang, Z., \& Zhou, N. (2005). Developing strategic orientation in China: Antecedents and consequences of market and innovation orientations. Journal of Business Research, no. 58, vol 8, p. 1049-1058.

Zulkepli, Z. H., Hasnan, N., \& Mohtar, S. (2015). Communication and Service Innovation in Small and Medium Enterprises (SMEs). Procedia-Social and Behavioral Sciences, no. 211, p. 437-441.

Submitted:

20.04.2018
Revised:

14.09.2018
Accepted and published online 17.09.2018 